This document is the preprint version of the article, and should be cited as:

Luca Chiapperino and Francesco Panese, 'Gendered Imaginaries: Situating Knowledge of Epigenetic Programming of Health', Sociology of Health \& Illness 40, no. 7 (1 September 2018): 1233-49, https://doi.org/10.1111/1467-9566.12779.

\title{
Gendered imaginaries: situating knowledge of epigenetic programming of health
}

\section{Introduction}

Recent discoveries in epigenetics, which support the developmental origins of health and disease (DOHaD) hypothesis (Barker and Osmond 1986), are currently generating a growing attention. Numerous studies are being conducted on the epigenetic mechanisms that are involved in gestational programming of health, as well as on the potential contribution of epigeneticallyacquired traits in relation to development and programming of individual health (Heindel and Vandenberg 2015; Szyf 2015). The central argument of DOHaD studies is that maternal-offspring dynamics in utero (or during lactation) can explain the origin of adult diseases in terms of metabolic programming of the foetus. In this respect, the body of the mother is regarded as a "vector" (Richardson and Stevens 2015, p.211), or a "capital" holder (Wells 2010, p.1) for the healthy development of the child. To this, studies of the epigenetic mechanisms of inheritance via the gametes - hence potentially both from the paternal and the maternal line (Blake and Watson 2016) - add the element of pre-conceptional pathways and exposures of prospective parents to the eventual programming of the offspring's health. Taken together, these various facets of $\mathrm{DOHaD}$ and epigenetic research tell a story about the biology of reproduction that brings together the responsiveness of the foetus to its environment (mediated by the mother), and the transmission of environmental influences (behaviours, biographies, or - most prominently in the literature traumas; see Yehuda et al. 2016) through parental germlines.

Needless to say, epigenetics and DOHaD extend far beyond the construction of a new scientific paradigm for gestational biology and human reproduction. Combining all of these emerging observations animates in fact also a regime of promises and desirable futures when it comes to reproduction, pregnancy and the relationship we entertain with future generations. In the coming years - it is argued, or at least imagined - parental influences on the health of future 
This document is the preprint version of the article, and should be cited as:

Luca Chiapperino and Francesco Panese, 'Gendered Imaginaries: Situating Knowledge of Epigenetic Programming of Health', Sociology of Health \& Illness 40, no. 7 (1 September 2018): 1233-49, https://doi.org/10.1111/1467-9566.12779.

generations will acquire a new, epigenetically-informed meaning. Prima facie, epigenetic evidence corroborating and expanding the $\mathrm{DOHaD}$ hypothesis purport that parental influences on the health of the new-born extend past the moment of conception, and are the result of non-genetic pathways of inheritance of biological predispositions. From effects of parental (and also grandparental) exposures, to in utero signalling and transduction of environmental influences, the picture drawn by epigenetics and $\mathrm{DOHaD}$ shapes a renewed understanding of reproductive practices, and promises to redefine how lifestyle choices and environmental hazards are likely to yield adverse health outcomes in the offspring. In doing so, $\mathrm{DOHaD}$ and epigenetics constitute a concrete, factual resource for articulating an imaginary (Ezrahi 2012; Jasanoff 2015) of reproduction and parenting, which is performed and produced (i) in technoscientific understandings of paternal and maternal influences before and after conception; (ii) through socio-economic entrepreneurship aimed at ameliorating marketed products and populational nutrition (Nestlé Corporate Media Relations 2014; Danone Nutricia Research 2016); (iii) or through pivotal policy commitments to modify "aspects of social structures, education, health, nutrition, and behaviour modification both before and after birth" (Gluckman et al. 2008; p.70), in order to meet the challenges of future global health (Pray 2015; World Health Organization et al. 2016).

Yet, vital to the establishment, reproduction and enactment of these emerging imaginaries is not just their capacity to project these scientific findings onto new demands for individual, or collective actions. Rather, understanding the socio-political and technoscientific orders they embed calls also for an account of the agency of knowledge-producers, or a cartography of how scientists in the field produce "facts" about $\mathrm{DOHaD}$ and epigenetics to construct elements for social, and political relations. This co-productionist stance (Jasanoff 2004) allows capturing the premises and standpoints that produce counterposed biological visions of pregnancy and reproduction through 
This document is the preprint version of the article, and should be cited as:

Luca Chiapperino and Francesco Panese, 'Gendered Imaginaries: Situating Knowledge of Epigenetic Programming of Health', Sociology of Health \& Illness 40, no. 7 (1 September 2018): 1233-49, https://doi.org/10.1111/1467-9566.12779.

epigenetics and $\mathrm{DOHaD}$, and that - in turn - demand rival adjustments in institutional, individual and collective agencies.

By gathering the perspectives of individual researchers in $\mathrm{DOHaD}$ and epigenetic sciences, our paper aims at dissecting the controversial elements, inconclusive bits and factual negotiations that scientists mobilize to diffract representations of the realities of pregnancy (in its relationship with parenthood) into norms, values, facts and responsibilities imagining future relationships among generations. The paper proceeds as follows. We firstly describe the place of questions regarding the relative weight of paternal and maternal influences on the health of the offspring in the discursive formalization of $\mathrm{DOHaD}$ and epigenetic research in scientific publications. This enables us to describe the mutual constitution of prototypes (i.e. experimental designs, settings, techniques) and stereotypes (i.e. social meanings, beliefs, norms and values) of parental roles in scientific discourses of $\mathrm{DOHaD}$ and epigenetic in biomedical sciences. In particular, our analysis shows how the paradigm of $\mathrm{DOHaD}$ and epigenetics rests upon, and consolidates a gendered figuration of maternal influences and responsibilities by resorting to the experimental construct of (what we call) the 'father-as-sperm'.

Second, and drawing from a set of interviews $(\mathrm{N}=15)$, we describe a tension between the discursive resources prominently figuring in scientific publications and the perspective of individual scientists. The situated perspective of individual researchers provides in fact evidence of a plethora of gendered engagements with the parental figurations currently animating DOHaD and epigenetic research, which suggest a more fine-grained as well as conflictual web of socio-political positioning of this "knowledge" within the scientific community. By delving into the role and centrality of scientists qua key actors producing the resources for the societal uptake of epigenetics and DOHaD, we wish to illuminate how this evidence partakes to the assemblage of rival imaginaries of parenting and reproduction. These imaginaries, as we show, are at "once products of and 
This document is the preprint version of the article, and should be cited as:

Luca Chiapperino and Francesco Panese, 'Gendered Imaginaries: Situating Knowledge of Epigenetic Programming of Health', Sociology of Health \& Illness 40, no. 7 (1 September 2018): 1233-49, https://doi.org/10.1111/1467-9566.12779.

instruments of the co-production of science, technology, and society in modernity" (Jasanoff, 2015: 19, emphasis added). First, they plastically display how distinct moral economies - specifically, the production and circulation of social values, norms and obligations (Fassin 2009, p.37) with regard to parenting, reproduction and gender imbalances - currently inspire epigenetic science practice, and the place individual scientists occupy in the field. Second, the performativity of this imagination on the side of experts is not confined only to individual ethical orientations, or to a source of inspiration in their daily work. Rather, the moral orders imagined by the participants to our study define the boundaries, priorities and objects of their scientific work, and thus shape distinct, often conflicting epistemic economies probing the epigenetic foundations of the DOHaD hypothesis.

\section{From prototypical to stereotypical parents in DOHaD and epigenetics}

The DOHaD hypothesis, also known as Barker's theory (Barker et al. 1989), posits that the origin of several illnesses (e.g. cardiovascular diseases, cancer, psychiatric disorders) should be found in the responses that the foetus (or the infant) makes to the plethora of cues from the mother, her health and her biophysical environment. Grounded on epidemiological evidences that poor nutrition during organism development correlates with an increased risk of (heart) disease later in life (Barker et al. 1989), the DOHaD hypothesis has been formulated in the mid-80s' (Barker and Osmond 1986), and has long circulated in the biomedical literature on gestational care, paediatric medicine and public health. However, only recent studies on epigenetic programming in early development have provided this epidemiological concept with a new molecular breadth (Godfrey et al. 2007).

In its narrow (and original) interpretation, the $\mathrm{DOHaD}$ hypothesis pointed to the possibility that the embryo, the foetus and the infant are under the influence of a constant signalling process 
This document is the preprint version of the article, and should be cited as:

Luca Chiapperino and Francesco Panese, 'Gendered Imaginaries: Situating Knowledge of Epigenetic Programming of Health', Sociology of Health \& Illness 40, no. 7 (1 September 2018): 1233-49, https://doi.org/10.1111/1467-9566.12779.

from the environment within which they develop. A broader interpretation of the DOHaD paradigm emerges instead from its intersection with epigenetics both in humans and animal models. New data (Miska and Ferguson-Smith 2016), and old ideas (Holliday 1987) are being combined (Daxinger and Whitelaw 2012; Szyf 2015) to expand the DOHaD paradigm at two different levels. First, the temporal scale of developmental programming, which is no longer confined to phenotypic traits acquired during development (i.e. the first 1000 days of our life), but rather includes epigenetic predispositions acquired before conception from both the parental lineages (i.e. from their own foetal environments onwards). Second, the expansion of DOHaD thinking pertains to the potential origin of developmental programming of health and disease. Besides the well-established literature on effects transduced by the mother during pregnancy, evidence of epigenetic inheritance through the male germline adds to the $\mathrm{DOHaD}$ paradigm the inheritance of non-genetic predispositions from the paternal line. The growing evidence of paternal effects is in fact vocalised, within the community of scientists, as encouraging researchers to think about the developmental contribution of "both parents" equally, or at least to acknowledge that the differential contribution of maternal and paternal epigenetic predispositions ought to be taken into account along with the gestational period when looking at the early origins of adult diseases (Wells 2014; Romanus et al. 2016).

Taken at face value, the increasing role assigned to paternal influences can be regarded as a promising aspect of this research that counterbalances "the tendency to pin poor outcomes on maternal behaviour" (Richardson et al. 2014, p.132), and shifts "the balance of responsibility for the unborn, away from the mother" (Whitelaw 2006, p.132). Yet, as we will see in the remainder of this section, several problematic aspects can be found in the ways the role of fathers is studied (prototyped), conveyed (stereotyped) within this literature, and consequently with regard to its relative weight and importance vis à vis maternal effects. 
This document is the preprint version of the article, and should be cited as:

Luca Chiapperino and Francesco Panese, 'Gendered Imaginaries: Situating Knowledge of Epigenetic Programming of Health', Sociology of Health \& Illness 40, no. 7 (1 September 2018): 1233-49, https://doi.org/10.1111/1467-9566.12779.

As showed extensively by feminist scholarship, the last few decades have witnessed the emergence of several dominant trends of reproductive politics positioning the unborn and the foetus as either "passively threatened by the maternal body or else as apparently independent from this body" (Lupton 2013, p.115). On the one hand, the focus on the potentially harmful behaviours of women has resulted in a gendered politics of reproductive choices that frames the interests of the unborn in opposition to those of the mother (Petchesky 1987; Franklin 1995). On the other hand, the advent of imaging (Sandelowski 1994), assisted reproduction (Strickler 1992) and genetic testing technologies (Reed 2009) has resulted in a moral discipline of reproduction demanding prospective mothers a pioneering role in the "quality control and normalization" of the unborn dictated by technoscience (Rapp 1999, p.307; see also Strathern 1992; Thompson 2005).

Within this context, epigenetic studies of developmental programming of health and disease are no exception, and can arguably be positioned in an innovating continuity with these established trends of gendered politics in reproduction. Martha Kenney and Ruth Müller (2016) have shown how researchers in behavioural epigenetics often "reinforce preheld ideas about the role of mothers in the psychological and physical health of their offspring" (p.8), and make brisk overstated conclusions as to the meaning of findings in animal models for the understanding of human problems with regard to mothering behaviours. This is a particularly cogent issue, as recognised also by others (Warin et al. 2011; Richardson and Stevens 2015; Lappé 2016), because it entails a simplistic understanding of parental influences, which both reduces the social complexity of this phenomenon to the dynamics observable in animal studies, and reinforces long-standing stereotypical treatments of maternal roles and responsibilities. The combination of the epigenetic and DOHaD models, however, does not only reproduce the expectations for a maternal responsibility to act upon biomedical knowledge to protect the developing foetus. Rather, it marks also a distinctive switch to two future-oriented perspectives. On the one hand, epigenetics and 
This document is the preprint version of the article, and should be cited as:

Luca Chiapperino and Francesco Panese, 'Gendered Imaginaries: Situating Knowledge of Epigenetic Programming of Health', Sociology of Health \& Illness 40, no. 7 (1 September 2018): 1233-49, https://doi.org/10.1111/1467-9566.12779.

$\mathrm{DOHaD}$ fold the wellbeing of several generations into the timeframe of pregnancy (Mansfield 2017). The epigenetic foetus demands protection from external hazards not just as an unborn child, but also as a prospective parent, since its germ cells start developing during pregnancy. Protecting the foetus thus becomes also protecting the progeny that this future person may engender. On the other hand, the multi-generational effects mediated by the gametes extend the cogency of social concerns for the unborn also to the pre-conceptional period, which is already the focus of much social and public health attention (Waggoner 2017). The pathways of epigenetic inheritance of disease risks and predispositions shift the onus of parental responsibilities to a temporal scale that extends beyond the time of pregnancy, to include claims in favour of protecting one's epigenome that apply to all individuals of reproductive age. In so doing, epigenetics and DOHaD incorporate the relevance of both the maternal and paternal germline, although the implication of paternal bodies in the consideration of pre-conceptional pathways for protecting fetal vulnerability still plays a very limited role (Waggoner 2017, p.21-2).

While we agree with these authors that "preconceptions about sex and gender" are pivotal also in epigenetic and $\mathrm{DOHaD}$ research - and that these "give rise to specific figurations of motherhood [...] that focus the responsibility/blame for the health of the offspring on the mother" (Kenney and Müller 2016, p.16) - we argue that another main explanation for the limited role of paternal influences in these works lies in the ways biological experiments can study parental care, and consequently produce discursive resources to know and norm this issue in our societies. A careful look at the experimental practice producing an emphasis on mothers (i.e. the female rodent and its human correspondent) reveals in fact that gendered preconceptions about the role of each parent can only partly account for the specific maternal figurations embedded in DOHaD and epigenetics. The construction of the 'mother-as-vector' (Richardson and Stevens 2015) - namely 
This document is the preprint version of the article, and should be cited as:

Luca Chiapperino and Francesco Panese, 'Gendered Imaginaries: Situating Knowledge of Epigenetic Programming of Health', Sociology of Health \& Illness 40, no. 7 (1 September 2018): 1233-49, https://doi.org/10.1111/1467-9566.12779.

the mother as the main mediator of influence on the offspring's health - is rather intrinsic to the material and experimental configuration of these scientific settings.

The following extract from the supplementary methods of the famous paper by the groups of Michael Meaney and Moshe Szyf at McGill University (Montreal, Canada) - investigating the effects of maternal behaviours (i.e. licking and grooming, arched-back nursing) on stress reactivity in rats (Weaver et al. 2004) - can help us better illustrate this point. Kenney and Müller draw from this paper to show how, by hypothesizing an epigenetic mechanism for the transmission of a predisposition for stress-coping, the McGill's scientists construct notions of motherhood as both channelling the effects of environmental stimuli on the offspring's health (i.e. the mediating mother), and extending far beyond pregnancy by hard-wiring such predispositions in the offspring's genome (i.e. the expanding mother). Yet, what the authors describe as a further instantiation of the interplay of social conceptions of maternal care or affection and experimental biology, is also a pragmatic abidance of these scientists to the standard practices of animal breeding and experimentation:

The animals were mated with males drawn randomly from a breeding stock maintained in our colony. [...] All procedures were performed according to guidelines developed by the Canadian Council on Animal Care and protocol approved by the McGill University Animal Care Committee (Weaver et al. 2004, Supplementary Methods, p.1).

Since the standard breeding configuration in animal houses (in Canada, but also in Europe and the $\mathrm{US}^{\mathrm{ii}}$ ) foresees that the male animal shall be "drawn" "from the breeding stock" to the same cage of the mother only for conception, the resulting emphasis on maternal effects appears to be partly due to the epistemic conditions for discerning influences from both parents. Paternal care is thus an understudied issue in epigenetics and $\mathrm{DOHaD}$ research not just because of the rarity of this 
This document is the preprint version of the article, and should be cited as:

Luca Chiapperino and Francesco Panese, 'Gendered Imaginaries: Situating Knowledge of Epigenetic Programming of Health', Sociology of Health \& Illness 40, no. 7 (1 September 2018): 1233-49, https://doi.org/10.1111/1467-9566.12779.

phenomenon in non-human mammals (Rilling and Young 2014), or because of the tendency of biologists to reduce human complexity to the controlled setting of the animal facility (Kenney and Müller 2016), or because of stereotypes wanting the well-being of children to be the sole responsibility of the mothers also in epigenetics and DOHaD (Warin et al. 2011; Richardson and Stevens 2015). Rather, another fundamental reason behind the gendered politics of (increased maternal) responsibility ascribable to $\mathrm{DOHaD}$ and epigenetics should be sought in the coproduction of prototypes (i.e. the standards of animal laboratory practice) used to investigate developmental programming and stereotypes (i.e. social meanings, beliefs, norms and values) of parental roles and responsibilities. Standards of breeding and weaning are far from being only a technical limitation of animal models. Rather they qualify as a fundamental determinant of the epistemic, technological and social imagination currently being experimented with in DOHaD and epigenetic research. They define research practices, constraint the testable hypotheses, and spread out as resulting "facts" about the respective influence of fathers and mothers, which strengthen long-standing views of the merely generative role of the formers, and the vital responsibility of the latters in the upbringing of the offspring.

In fact, a seminal work by Carol Delaney (1986) already put forth the argument that western societies rely upon a Christian and monogenetic view of procreation, whereby paternity is understood as begetting or simply generating the offspring, while maternity is instead characterized as the physiological nourishment of child development. This account has later found its correspondence in the skewed emphasis between "genetic and gestational contributions", which several authors have documented empirically in the practices and problems associated with reproductive biotechnologies (Rapp 1999, p.88; see also Hallowell et al. 2006; Reed 2009). To these perspectives, our analysis adds the recognition that also epistemic standards in biological studies of parental effects engender a primacy of mothering in the transmission of health 
This document is the preprint version of the article, and should be cited as:

Luca Chiapperino and Francesco Panese, 'Gendered Imaginaries: Situating Knowledge of Epigenetic Programming of Health', Sociology of Health \& Illness 40, no. 7 (1 September 2018): 1233-49, https://doi.org/10.1111/1467-9566.12779.

predispositions and risks to the progeny. Even though an increasing number of studies in epigenetics (Day et al. 2016) and DOHaD (Wells 2014; Romanus et al. 2016) gives fathers an ever larger and more active role, it is crucial noting how the technological artefact of the animal house is a decisive factor in the distribution of responsibilities and agency for the promotion of future generations' wellbeing. Studies of parental effects in epigenetics and DOHaD operate therefore not only under a stereotypical narrative of fathers as mere germline resource for the development of the offspring, and maternal bodies as the modulators of future generations' health. Rather, the constraining prototype of (what could be called) the father-as-sperm distils a specific set of testable hypotheses obliterating the role of fathers in the upbringing of the progeny, and thus lends legitimacy to related stereotypes of parental roles. In other words, epigenetic research is both fuelling and being fuelled by preconceptions about women's role in society when drawing from the heuristic construction of the father being reduced solely to the qualities and attributes of sperm. This is the complementary explanation we provide for the gendered politics of reproduction prompting an increased control on women's bodies, choices, and lifestyles entailed in DOHaD and epigenetic biosciences (Warin et al. 2011; Richardson and Stevens 2015; Kenney and Müller 2016). By paraphrasing Meloni (2016, p.219), the scientific discourse around DOHaD and epigenetics allows not only its characterization as a "sexist society" hijacking "scientific research for its own goals", but also suggests a moment of co-production between the pragmatic exclusion of the male in animal studies and the obliteration of fathers' role in the epistemic and social imagination entrenched in this research.

\section{Talking of maternal and paternal influences with researchers in DOHaD and epigenetics}

Our interviews were conducted as part of a project exploring how developments in epigenetics and DOHaD partake to a public discourse renegotiating responsibilities to protect the wellbeing of 
This document is the preprint version of the article, and should be cited as:

Luca Chiapperino and Francesco Panese, 'Gendered Imaginaries: Situating Knowledge of Epigenetic Programming of Health', Sociology of Health \& Illness 40, no. 7 (1 September 2018): 1233-49, https://doi.org/10.1111/1467-9566.12779.

future generations. All interviews $(\mathrm{N}=15)$ were conducted face-to-face with researchers working on epigenetic programming of health from a variety of disciplinary perspectives, such as epigenomics, behavioural epigenetics, social epigenetics, epigenetic epidemiology, paediatric and gestational medicine. The informants were selected to provide a balanced gender perspective ( 8 women, 7 men), and no researcher openly identifying him/herself with other genders than "man", or "woman" was identified by the authors. The interviewees span across different positions in the academic hierarchy, with a prevalence $(\mathrm{N}=9)$ of professors (full or associate) over post-doctoral and research fellows $(\mathrm{N}=6)$. The interviews took place in Switzerland, and they involved mainly researchers working for the main biomedical institutions of the country (i.e. universities and university hospitals), with the exception of two researchers being based in the US, and one in Sweden. All interviewees have been de-identified in the present manuscript by the use of initials.

Questions were asked starting from a guide devised among the authors. Notably, the questions were often raised in different orders, so as to keep the conversation unstructured, and leave respondents the possibility to identify the subject matters of utter concern. Nevertheless, all interviewees were in the end confronted with the same questions, ranging from how and why they started to be interested in epigenetics, to what kind of limitations (methodological, technical, conceptual) they see in their work and that of their colleagues, to more speculative reflections as to the socio-political uptake of their research. This latter set of questions was aimed at elucidating the implicit and explicit (social, political, epistemic) assumptions that these actors use to imagine a place and a role for "knowledge" of $\mathrm{DOHaD}$ and epigenetics in the wider society. The hypotheses from which the study took off were: (i) accumulating evidence in the field is intrinsically normative as it embeds simultaneously a vision of technoscience and social orders for reproductive and parental practices; (ii) not all the stakeholders in the debate imagine the same future for this knowledge. Thus, our conversations with respondents were directed at highlighting the knowledge- 
This document is the preprint version of the article, and should be cited as:

Luca Chiapperino and Francesco Panese, 'Gendered Imaginaries: Situating Knowledge of Epigenetic Programming of Health', Sociology of Health \& Illness 40, no. 7 (1 September 2018): 1233-49, https://doi.org/10.1111/1467-9566.12779.

claims and visions currently debated in the field, which in turn constitute rival epigenetic imaginaries of past, present and future relationships between generations.

When encouraged to talk about the intrinsic normativity of their research, our interviewees recognised how their practices partake to the fabrication, or perhaps reconfiguration of parental responsibilities in the moral economies of contemporary reproduction. Here we focus only on one bit of such complex puzzle: the one that sheds a critical look on DOHaD and epigenetics as to their impact on women's body and the (re)production of responsibilities of fathers and mothers for the wellbeing of future generations. When asked about whether an alleged, pre-existing emphasis on women's bodies drives $\mathrm{DOHaD}$ and epigenetic research, our interviewees gave answers pointing to their own responsibilities as researchers to avoid putting further societal emphasis on pregnancy and the maternal body. In particular, some of our women respondents expressed a specific engagement with this issue, which points to their role as scientists:

That is a very important question. I think the answer depends on how researchers, like me, design their studies; what kind of questions do we try to answer. If everyone constantly tries to answer questions that feed into the emphasis on the mother, then yeah...anything can hardly go into the direction of challenging anything. [...] We should take up a responsibility to inquiry what is the role of fathers and not only mothers. (G.S., woman, post-doctoral fellow; emphasis added).

The first theme emerging from our interviews relates to how respondents approached the issue of gender imbalances in the literature on $\mathrm{DOHaD}$ and epigenetics from their own distinct gendered perspectives. Women researchers tended to vocalise this issue as "having to do our best" (BO.M., woman, professor), or as matter of concern for them, as both researchers and women: 
This document is the preprint version of the article, and should be cited as:

Luca Chiapperino and Francesco Panese, 'Gendered Imaginaries: Situating Knowledge of Epigenetic Programming of Health', Sociology of Health \& Illness 40, no. 7 (1 September 2018): 1233-49, https://doi.org/10.1111/1467-9566.12779.

\begin{abstract}
We have a responsibility as researchers and women to shape, within certain limits, the perception of the real mechanisms underlying parental responsibilities. So if it is true that one part is on the father, it's absolutely our task to try to go deeper on this. Or at least, try not to prevent the advancement of this knowledge by brushing over the collection of data from both fathers and mothers. (S.S., woman, research fellow; emphasis added)
\end{abstract}

Things stand differently when we take into account the answers that male researchers gave to the same question about rebalancing the current attention on women's bodies. With the exception of one respondent - who emphasized the importance of the whole familial milieu as the relevant experimental setting to understand developmental programming of health - most men interviewees pointed at the heuristic power of the mother-child unit in pregnancy, and emphasized collective action for remedying to problematic narratives of motherhood permeating DOHaD and epigenetic research:

Of course, both parents are important. [...] But I think that the interest lies in pregnancy, and that's why we do more studies on women. [...] We hope that this may improve responsibility, but hopefully it won't increase guilt. [...] I see it more as a collective responsibility as a society, to organize its life in order to avoid this. (S.U., man, professor; emphasis added).

Defending, or questioning the heuristic value of gestational effects is thus a crucial question in the establishment of our interviewees' views about their responsibilities to challenge the entanglements between factual claims and socio-political figurations of parental roles in research practices. On the one hand, some of our respondents - notably, woman respondents - felt that establishing a balanced perspective on the contribution of each parent falls within the scope of their responsibilities as mothers, researchers, or women who are more empowered than others. Indeed, several women 
This document is the preprint version of the article, and should be cited as:

Luca Chiapperino and Francesco Panese, 'Gendered Imaginaries: Situating Knowledge of Epigenetic Programming of Health', Sociology of Health \& Illness 40, no. 7 (1 September 2018): 1233-49, https://doi.org/10.1111/1467-9566.12779.

interviewees often qualified their answers as coming from someone who "has been pregnant recently" (G.S., woman, post-doctoral fellow), or "has had a child" and thus "knows what it feels like" to be under others' scrutiny for her behaviour (S.S, woman, research fellow), or sheds her gaze on this matter "primarily as a woman, and then as a researcher" (BO.M., woman, professor). On the other hand, not all of our respondents felt personally concerned by the need to rebalance the stigma attracted by pregnant bodies. Most of our man interviewees tended in fact to deem crucial the focus on development (and consequently on pregnancy), and to refer to the collective responsibilities we all hold for making sure that this does not turn into an increased culpability of women in a pregnant state. Interestingly, this did not qualify as a lack of consideration, on the side of male interviewees, for the potential redressing of problematic individual (parental) responsibilities ${ }^{\mathrm{iii}}$ emerging from $\mathrm{DOHaD}$ and epigenetics. Besides the example cited above, many of our respondents were worried about how heralding such knowledge as a moral and policy "imperative to provide a healthy start to life for the next generations" (Hanson and Gluckman 2011: S5) comes with the downside of introducing new "pre-conceptional responsibilities" (A.J.B., man, paediatrician), and with reinforcing societal scrutiny of pregnant bodies.

Yet, a major difference can be found in the motivations provided by our respondents for avoiding the responsibilization of individuals, and especially mothers, with regard to their epigenetic legacy. While most men scientists adopted a third-person perspective - displacing any condemning evaluation of increased responsibilities for health produced by epigenetics and $\mathrm{DOHaD}$ outside of their labs into "society" - the standpoints of women scientists constituted a personal imperative to adopt a critical stance in which the epistemic and moral engagements with this matter are eminently blurred: 
This document is the preprint version of the article, and should be cited as:

Luca Chiapperino and Francesco Panese, 'Gendered Imaginaries: Situating Knowledge of Epigenetic Programming of Health', Sociology of Health \& Illness 40, no. 7 (1 September 2018): 1233-49, https://doi.org/10.1111/1467-9566.12779.

I think I have a responsibility as a woman and as a researcher. I feel touched by these questions and I feel responsible to make studies that may redress sexism with regard to the body of women, or mothers. But I think it is also difficult to get there: people in research are sexist, people who give the money for research are sexist...so, it's complicated to find a way out. (G.S., woman, post-doctoral fellow)

Following up on these affirmations, we then asked respondents to elaborate upon potential strategies to address the "critical issue" (M.I., woman, professor) of gender imbalances in DOHaD and epigenetic research in the establishment of their own research priorities. This brings us to the second major theme emerging from our interviews, which relates to how the gendered perspectives highlighted above operate a discernment of epistemic priorities; namely, they define relevant experimental resources, hypotheses, and call for "facts" dispatching paternal and maternal influences. Interestingly, the conversation happening at the interview prompted in one of our interviewees (a researcher in social epidemiology) a reflection about a grant proposal on which she was working at the moment:

I think that the emphasis on the mother drives many of these studies. I myself am setting up a study, and I am realizing now that I am not considering the father at all. Not willingly, I just didn't think about that! I think it is unfortunately something that is so rooted in society...I have discussed about my project with many people, and no one ever mentioned the father. If I hadn't had this conversation, data about fathers wouldn't have been included in my project. (S.S, woman, research fellow).

But besides this episode, which hints at the critical performativity of the mutual engagement between social and natural sciences (Rose 2013), the issue of establishing hypotheses, experiments, 
This document is the preprint version of the article, and should be cited as:

Luca Chiapperino and Francesco Panese, 'Gendered Imaginaries: Situating Knowledge of Epigenetic Programming of Health', Sociology of Health \& Illness 40, no. 7 (1 September 2018): 1233-49, https://doi.org/10.1111/1467-9566.12779.

datasets, samples that go in the direction of breaking the dangerous circular referencing between stereotypes and prototypes of parenthood (like those identified in the previous section) emerged as a remarkably urgent matter for the future of $\mathrm{DOHaD}$ and epigenetic studies among our female respondents. Answering to a question about the future directions of her research, one of our interviewees gave the following answer:

Father's nutrition! I would like to investigate father's nutrition prior to conception. For instance, in the project I am involved in we have data obtained from questionnaires about nutrition of mothers before conception. But we have no data from fathers. I have to say that I don't feel at all alone in this thing. (G.S., woman, post-doctoral fellow)

As to the motives prompting such inclusion of data on fathers into studies of the epigenetic mechanisms of developmental origins of diseases, respondents expressed the conviction that this choice is a matter of resistance to the expanding emphasis on women in this literature. As asserted by a researcher who is both the head of a hospital unit on genetic counselling, and the principal investigator of a research group looking at the epigenetic effects of toxic chemicals on sperm:

Father's age, a bit for the sake of feminism, is something that I tend to put on the table very often. [...] I do it for the sake of [making father's role] soak through society, but I don't think it will catch on. Even today, with non-invasive testing the mother-child "chimerism" makes more and more powerful the stereotypes that are fed by epigenetics. (G.A., woman, professor; emphasis added).

To further show how a solid engagement with gender imbalances can be observed among scientists in the fields of epigenetics and $\mathrm{DOHaD}$, the answer of a principal investigator - who has an established expertise on studies of transgenerational epigenetic effects - may be worth mentioning 
This document is the preprint version of the article, and should be cited as:

Luca Chiapperino and Francesco Panese, 'Gendered Imaginaries: Situating Knowledge of Epigenetic Programming of Health', Sociology of Health \& Illness 40, no. 7 (1 September 2018): 1233-49, https://doi.org/10.1111/1467-9566.12779.

here. According to her, concentrating on germ line-mediated effects operates a shift that is likely to shy away the field from its emphasis on the maternal body. "I am a woman who is saying to her colleagues that they have been wrong in focusing only on pregnancy", she argues, before answering to our question on the limitations of (what we called) the prototypical role of father-as-sperm in her experimental setting:

[Germ-line effects are] the key thing. If it's in the germ cells the consequences are totally different. It's another world, it's another field of medicine. It's epigenetic reproductive biology: the studies that need to be done and the data to be collected are very different. If it's based on RNAs, or methylation in sperm, you have to look at the epigenome across lifetime in the germ cells from both parents $[\ldots]$. It's a different type of research showing that gestational effects are not all that matters. (M.I., woman, professor; emphasis added).

Thus, our interviews show how looking at the interplay of prototypes and stereotypes of parental effects in DOHaD and epigenetics through the situated perspective of individual scientists reveals rather distinct economies of values, norms, and obligations (Fassin 2009), which these actors currently imagine for the socio-political moment of this knowledge. Our respondents suggest that their research is not merely (re)producing a circular referencing between pre-held ideas of vital mother-offspring relationship and marginalisation of paternal effects. Rather, the perspective of scientists in the field reveals a plethora of visions, connections, relationships, values, and unexpected openings to address the epigenetic legacy of health predispositions. Figure 1 is intended to show such complexity by positioning our respondents with regard to (1) their own responsibility to address this issue (y-axis), and (2) the extent to which rebalancing the emphasis on mothers (by, for instance, studying paternal effects) is one of their epistemic priorities (i.e. it is part of their study designs, research questions, hypothesis) (x-axis). Looking at this graph is particularly indicative of 
This document is the preprint version of the article, and should be cited as:

Luca Chiapperino and Francesco Panese, 'Gendered Imaginaries: Situating Knowledge of Epigenetic Programming of Health', Sociology of Health \& Illness 40, no. 7 (1 September 2018): 1233-49, https://doi.org/10.1111/1467-9566.12779.

the complexity and fragmentation of moral imagination that characterizes not only our respondents as a group, but also each of them as individuals. While a general trend can be observed for gendered engagements of women and men researchers respectively with these matters, it is also worth noting how even the answers of individual respondents within single interviews often contrast with one another.

[Figure 1 around here]

This finding allows both problematizing the context of the interview at issue, and its capacity to unveil the exercises of moral and epistemic imagination among our respondents. As to the former issue, the contrasting responses of our interviewees can be attributed to the unusual confrontation, by means of the interview, with a direct and in-depth reflection about their work and its "social implications", as they often vocalised the purpose of our encounter. As one of the informants put it:

It's very difficult to think about all this. [Long pause]. Honestly I am so into my research that I haven't even taken some time to step back and think about this situation, or kind of issues...one thing that I can say is that we need some thinking about this [she laughs]. [Long pause]. These are probably arguments that are going to feed debates about poverty in our societies [and its effects on health], as well as policy recommendations. (G.S., woman, post-doctoral fellow).

The context of the interview prompted reflections about the broader socio-political reverberations of epigenetics and $\mathrm{DOHaD}$, which our respondents characterize as being an exercise without precedents, or without a recognisable place in the ordinary course of their activities as scientists. In other words, the situation of the face-to-face interview put them in the uncommon situation of openly discussing "big” (S.M., man, professor), "tough questions" (B.M., man, professor), whose 
This document is the preprint version of the article, and should be cited as:

Luca Chiapperino and Francesco Panese, 'Gendered Imaginaries: Situating Knowledge of Epigenetic Programming of Health', Sociology of Health \& Illness 40, no. 7 (1 September 2018): 1233-49, https://doi.org/10.1111/1467-9566.12779.

answers are uncertain, ramified and perhaps also dictated by the need to conform to social expectations with regard to the use of their research in the social space. This produced a specific configuration of intersectionality (Collins 1998) in the empirical data we elicited from these interviews. Although, for instance, the respondent above recognizes the wider implications of epigenetics and DOHaD for our collective understanding of the biological effects of socioeconomic status, we could not observe a vocalization of issues of women's responsibilization as being connected to other social categories imbricated with a gendered politics of reproduction. As many have argued (Mansfield 2012; Mansfield and Guthman 2015; Meloni 2017), the turn towards a gendered and individualized optimization in epigenetics intersects in fact with several other societal issues, such as racialized questions about abnormality and pathologisation of social status. The responsibilization of individuals with respect to the protection of their epigenome is, according to this view (Mansfield 2012), not moving us from fixed racial differences to a plastic understanding of biological variation (Mansfield and Guthman 2015). Rather, it entails the corollary of a racialized pressure to conform to a privileged and idealized (white) norm, as well as the intensification of arguments for biological differences in our societies that can be qualified as an "embodied race" (Mansfield 2012, p.356). Perhaps due to the limited engagement of our respondents with the normativity entrenched in their scientific activity, our interviews elicited answers showing a thin and under-theorized reflexivity upon the mutual constitution of axes of social discrimination, which did not allow further problematizing the co-construction of socioeconomic, racialized and gendered political categories in epigenetics and DOHaD.

Yet, it is also worth noting the capacity of our interviews to reveal how exercises of moral and epistemic imagination intertwine in the activities of researchers in DOHaD and epigenetics. The patchy responses reported in Figure 1 are thus indicative of the unstructured nature, rather than the absence of such imagination in the work of our respondents. Interestingly, while the 
This document is the preprint version of the article, and should be cited as:

Luca Chiapperino and Francesco Panese, 'Gendered Imaginaries: Situating Knowledge of Epigenetic Programming of Health', Sociology of Health \& Illness 40, no. 7 (1 September 2018): 1233-49, https://doi.org/10.1111/1467-9566.12779.

respondent cited above claims not to be particularly reflexive as to the moral, social and political moment of her research, she followed these very same thoughts by affirming (i) that she "hope[s] [her] research will contribute to these [policy translations]" and (ii) by emphasizing her responsibility as woman and researcher to redress gender imbalances produced by $\mathrm{DOHaD}$ and epigenetic research (as testified by other excerpts of the same interview further above). This means that, while placing the respondents in an unusual engagement with these matters, the interviews managed to bring into light at least some of the hidden premises and moral standpoints which structure key aspects of knowledge-production in epigenetics and $\mathrm{DOHaD}$.

Specifically, our interviews show that scientists' engagements with the role of parents in the epigenetic programming of the child's health escape their reduction to a simple fabrication of figurations such as the 'mother-as-vector' (Richardson and Stevens 2015; Kenney and Müller 2016) and the 'father-as-sperm' detectable at its discursive level. First, DOHaD and epigenetics are among some of our respondents, and notably male researchers - an element to bring with caution into the existing moral economies (i.e. webs of expectations, values and norms inhabiting the social space; see Fassin 2009) of reproductive practices. For them, the problem is not naturalizing stereotypical parental roles, but rather ensuring that the percolation of their knowledge into norms and values for reproduction comes with a fair distribution of obligations and responsibilities across genders, socio-economic positions, and existing inequalities. By contrast, other interviewees prominently, women researchers - describe their research as a resource to contest uncomfortable stereotypes and rebalancing pre-existing views of paternal and maternal influences. The issue, for them, rather comes down to their own accountability and responsibility (as women, mothers, researchers) to test the relative influence of each parent, in order to break the reiteration of moral judgements and imperatives (i.e. stereotypes) focusing only on women's reproductive bodies. These interviews thus flesh out at least two types of gendered perspectives, among scientists, which 
This document is the preprint version of the article, and should be cited as:

Luca Chiapperino and Francesco Panese, 'Gendered Imaginaries: Situating Knowledge of Epigenetic Programming of Health', Sociology of Health \& Illness 40, no. 7 (1 September 2018): 1233-49, https://doi.org/10.1111/1467-9566.12779.

project the study of $\mathrm{DOHaD}$ and epigenetics into alternative visions of individual agency and collective living. While the normativity embedded in the perspectival work of these "experts" may not differ in terms of prescriptive affirmations and suggested regulatory options ${ }^{\mathrm{iv}}$, clearly these scientists provide distinct understandings - starting from their own position as experts, women, men, parents, citizens - of their role and responsibilities in carving out alternative moral economies (Fassin 2009) of epigenetics and DOHaD for reproduction and pregnancy.

Second, and very much related to the first element, several of our female interviewees also appear to approach the question of their responsibility to intervene upon these moral economies by questioning their experimental practices. That is, the scientific ethos of remedying to gender imbalances in their research is not only a moral bond with other (less empowered) women, but also an imperative to rethink the existing models, experiments, and datasets (i.e. prototypes) finally accounting for the relative weight of paternal and maternal influences over the offspring. While our interviewees may differ in the way they put into practice such imperative, an element they share is thus the need to problematize (what we call) the epistemic economies of DOHaD and epigenetics. That is - if we wanted to paraphrase Fassin (2009, p.37) - the production, distribution, circulation, and use of hypotheses, experimental settings, techniques and datasets, which are aimed at informing a less gendered economy of norms, values and obligations produced by $\mathrm{DOHaD}$ and epigenetic research. In our understanding ${ }^{\mathrm{v}}$, these interviews reveal in fact a symmetric, material and epistemic instantiation of the moral economies shaping and spreading out of these practices of knowledgeproduction and scientific practices. From the need of integrating data about fathers in epidemiological studies of mother-child pairs, to the goal of advancing knowledge on fathers' nutrition before conception, some of our respondents break loose the cycle of judgements and imperatives (i.e. stereotypes), scientific practices, models and "facts" currently co-producing an economy of surveillance and stigmatization of pregnant bodies in $\mathrm{DOHaD}$ and epigenetics. And 
This document is the preprint version of the article, and should be cited as:

Luca Chiapperino and Francesco Panese, 'Gendered Imaginaries: Situating Knowledge of Epigenetic Programming of Health', Sociology of Health \& Illness 40, no. 7 (1 September 2018): 1233-49, https://doi.org/10.1111/1467-9566.12779.

they do so by means of the material resources, laboratory equipment and statistical tools that pertain to their respective disciplines. Thus, the constraining prototype of what we called the father-assperm turns, for some of our respondents, into an experimental resource to dismantle the conflictual web of norms and obligations investing mothers with an increased responsibility to care for the epigenetic predispositions acquired in utero. At the same time, the innovative integration of paternal data in epigenetic epidemiological cohorts, brings the question of such gender imbalances to the level of the standard conditions of knowledge-production and experimental practice of this type of science. The assemblage of these economies of data, techniques, hypotheses and research questions is, in other words, a decisive element that researchers mobilize for contesting the axes of domination in the ethos of parenting and reproduction, which both informs and draws its legitimacy from practices of knowledge-production in $\mathrm{DOHaD}$ and epigenetics. And for this reason, it constitutes the indication of a substantive conflict not only around the values, but also around the facts imagining the future of reproductive and parental practices from within these fields of biomedical research.

\section{Conclusions}

The role assigned to the mother in epigenetics and $\mathrm{DOHaD}$ research is no doubt a controversial element of this emerging scientific discourse, as already recognised by its critical examinations in STS, feminist and anthropological writing (Warin et al. 2011; Richardson and Stevens 2015; Kenney and Müller 2016). The result of this emphasis on the mother as “vector", is that women's bodies are yet again conceptualized as disposable loci for public health intervention, as targets for political fantasies of surveillance and amelioration of the health of future generations (Rapp 1999).

In our paper, we integrated these views by showing how the gendered politics of reproduction in epigenetics and $\mathrm{DOHaD}$ pertains both to the upstream stereotypes (i.e. social 
This document is the preprint version of the article, and should be cited as:

Luca Chiapperino and Francesco Panese, 'Gendered Imaginaries: Situating Knowledge of Epigenetic Programming of Health', Sociology of Health \& Illness 40, no. 7 (1 September 2018): 1233-49, https://doi.org/10.1111/1467-9566.12779.

meanings, beliefs, norms and values) that currently inform the experimental practice in this field, and the material, experimental resources used to investigate developmental programming. The constraining prototype of (what we called) the father-as-sperm shows that the technical limitations of animal research, standards of breeding and weaning are a fundamental determinant of the epistemic and moral imagination currently pervading $\mathrm{DOHaD}$ and epigenetic research.

We then moved to a qualitative analysis of individual researchers' perspective on the contested normativity enshrined in their research. This allowed us to capture the upstream beliefs, norms and values that currently partake to the construction of the moral and epistemic economies animating this field of biomedical sciences. And, at the same time, to highlight how the competing gendered perspectives within the community of scientists working in $\mathrm{DOHaD}$ and epigenetics constitute a diffraction grid with which distinct ways of representing and studying the role of parental influences on the health of the newborn are currently pursued. Plunging into the situatedness of knowledge-producers in this field reveals, in other words, how competing moral and epistemic controversies intertwine in the production of this evidence for the sake of its translation into reproductive and parental practices.

Our results posit therefore a tension between the agency, objectives, and values of individual scientists and their formalization into a dominant, objectifying molecular discourse for women and their role as pregnant bodies. In particular, our work exposes how single researchers in the field challenge the reading of $\mathrm{DOHaD}$ and epigenetics as the fabric of more stringent mothering roles, and (even more) moralised female bodies. Juxtaposing our findings to the stereotypical roles of 'mother-as-vector' (Richardson and Stevens 2015) and 'fathers-as-sperm' that populate scientific writing in the field rather suggests that, far from being a fait accompli, the imaginaries of reproduction spreading out of $\mathrm{DOHaD}$ and epigenetics are presently a matter of dispute among scientists too. And they appear to be a contested subject also at the level of the resources used and 
This document is the preprint version of the article, and should be cited as:

Luca Chiapperino and Francesco Panese, 'Gendered Imaginaries: Situating Knowledge of Epigenetic Programming of Health', Sociology of Health \& Illness 40, no. 7 (1 September 2018): 1233-49, https://doi.org/10.1111/1467-9566.12779.

the priorities set by actors in this field of research. From the relative weight to be assigned to paternal influences, to the balancing of the differential effects of egg-dependent vs. spermdependent epigenetic inheritance, our paper shows that practices of knowledge-production are the relevant loci of observation for adversarial imaginations of the economy of values, norms and moral sentiments invested by DOHaD and epigenetics. 
This document is the preprint version of the article, and should be cited as:

Luca Chiapperino and Francesco Panese, 'Gendered Imaginaries: Situating Knowledge of Epigenetic Programming of Health', Sociology of Health \& Illness 40, no. 7 (1 September 2018): 1233-49, https://doi.org/10.1111/1467-9566.12779.

\footnotetext{
${ }^{\mathrm{i}}$ We will not delve here into the problematic dualistic view of parental roles that permeates studies in DOHaD and epigenetics. For a thorough analysis of the flawed societal definitions of sex, gender and their epistemic underpinnings, see: Fausto-Sterling, 1992. For a critique of the power of scientific representations to naturalize social conventions about gender, see instead: Martin 1991.

${ }^{\text {ii }}$ For the Canadian guidelines mentioned by Weaver and colleagues, see: (Canadian Council on Animal Care 2003). The same standards can be identified in the European Directive 2010/63 (European Parliament and European Council 2010, p.57), as well as in the "Guide for the Care and Use of Laboratory Animals" (National Research Council 2011) laying out standards for animal experimentation in the EU and the US.

${ }^{\text {iii }}$ For an analysis of the mutual shaping between moral exercises of individual responsibility for health and epigenetic research, see: Chiapperino and Testa 2016. For a normative critique of claims of epigenetic responsibility, see: Hedlund 2011; Chadwick and O’Connor 2013; Dupras and Ravitsky 2016.

${ }^{\text {iv }}$ As shown above, a shared urge can be found (among many of our interviewees) to avoid further igniting public health surveillance on the body of the mother.

v Although the term has been already used by other authors (Medina 2011; Pugliese 2012), we consider 'epistemic economies' to be less the ideological premises and "constitutive features" (Medina 2011, p.31) of science in a sociocultural context, than the reconfigurations of scientific practices dictated by the values, norms and moral stances embraced by researchers. In this respect, our 'epistemic economies' are more cognate to the notion of 'moral economies of science' discussed by Lorraine Daston (Daston 1995; Fassin and Lézé 2014, chapter 28), to which our use of the adjective 'epistemic' adds an emphasis on the concrete hypotheses, material resources and experimental recompositions operated by the ethos of scientists as both individuals and a community.
}

\section{Bibliography}

1. Barker, D. J. P., and C. Osmond. 1986. Infant Mortality, Childhood Nutrition, and Ischaemic Heart Disease in England and Wales'. The Lancet 327 (8489): 1077-81.

2. Barker, D. J. P, C Osmond, P. D Winter, B Margetts, and S. J Simmonds. 1989. 'Weight in Infancy and Death from Ischaemic Heart Diseases'. The Lancet 334 (8663): 577-80. 
This document is the preprint version of the article, and should be cited as:

Luca Chiapperino and Francesco Panese, 'Gendered Imaginaries: Situating Knowledge of Epigenetic Programming of Health', Sociology of Health \& Illness 40, no. 7 (1 September 2018): 1233-49, https://doi.org/10.1111/1467-9566.12779.

3. Blake, Georgina ET, and Erica D Watson. 2016. 'Unravelling the Complex Mechanisms of Transgenerational Epigenetic Inheritance'. Current Opinion in Chemical Biology 33 (August): $101-7$.

4. Canadian Council on Animal Care. 2003. Guidelines on: Laboratory Animal Facilities Characteristics, Design and Development. Ottawa: Canadian Council on Animal Care.

5. Chadwick, Ruth, and Alan O’Connor. 2013. 'Epigenetics and Personalized Medicine: Prospects and Ethical Issues'. Personalized Medicine 10 (5): 463-71.

6. Chiapperino, Luca, and Giuseppe Testa. 2016. 'The Epigenomic Self in Personalised Medicine: Between Responsibility and Empowerment'. In Biosocial Matters: Rethinking the SociologyBiology Relations in the Twenty-First Century, Wiley-Blackwell, 616. Sociological Review Monograph. Wiley-Blackwell.

7. Collins, Patricia Hill. 1998. 'It's All in the Family: Intersections of Gender, Race, and Nation'. Hypatia 13 (3): 62-82.

8. Danone Nutricia Research. n.d. 'Nutricia Research | Danone Nutricia Research'. Nutricia Research. Accessed 26 October 2016. http://www.nutriciaresearch.com/.

9. Daston, Lorraine. 1995. 'The Moral Economy of Science'. Osiris 10: 2-24.

10. Daxinger, Lucia, and Emma Whitelaw. 2012. 'Understanding Transgenerational Epigenetic Inheritance via the Gametes in Mammals'. Nature Reviews Genetics 13 (3): 153-62.

11. Day, Jonathan, Soham Savani, Benjamin D. Krempley, Matthew Nguyen, and Joanna B. Kitlinska. 2016. 'Influence of Paternal Preconception Exposures on Their Offspring: Through Epigenetics to Phenotype'. Am J Stem Cells 5 (1): 11-18.

12. Delaney, Carol. 1986. 'The Meaning of Paternity and the Virgin Birth Debate'. Man 21 (3): 494.

13. Dupras, Charles, and Vardit Ravitsky. 2016. 'The Ambiguous Nature of Epigenetic 
This document is the preprint version of the article, and should be cited as:

Luca Chiapperino and Francesco Panese, 'Gendered Imaginaries: Situating Knowledge of Epigenetic Programming of Health', Sociology of Health \& Illness 40, no. 7 (1 September 2018): 1233-49, https://doi.org/10.1111/1467-9566.12779.

Responsibility'. Journal of Medical Ethics, March, medethics-2015-103295.

14. European Parliament, and European Council. 2010. Directive 2010/63/EU of the European Parliament and of the Council of 22 September 2010 on the Protection of Animals Used for Scientific Purposes. Vol. Official Journal of the European Union L 276. http://eurlex.europa.eu/legal-content/EN/TXT/PDF/?uri=CELEX:32010L0063\&from=EN.

15. Ezrahi, Yaron. 2012. Imagined Democracies: Necessary Political Fictions. Cambridge University Press.

16. Fassin, Didier. 2009. 'Moral Economies Revisited'. Annales. Histoire, Sciences Sociales 64th Year (6): 1237-66.

17. Fassin, Didier, and Samuel Lézé. 2014. Moral Anthropology: A Critical Reader. Routledge.

18. Franklin, Sarah. 1995. 'Postmodern ProCreation: A Cultural Account of Assisted'. Conceiving the New World Order: The Global Politics of Reproduction, 323.

19. Gluckman, Peter, Mark Hanson, Cyrus Cooper, and Kent L. Thornburg. 2008. 'Effect of in Utero and Early-Life Conditions on Adult Health and Disease'. New England Journal of Medicine 358: 6173.

20. Godfrey, Keith M, Karen A Lillycrop, Graham C Burdge, Peter D Gluckman, and Mark A Hanson. 2007. 'Epigenetic Mechanisms and the Mismatch Concept of the Developmental Origins of Health and Disease'. Pediatric Research 61 (5 Part 2): 5R-10R.

21. Hallowell, Nina, Audrey Arden-Jones, Ros Eeles, Claire Foster, Anneke Lucassen, Clare Moynihan, and Maggie Watson. 2006. 'Guilt, Blame and Responsibility: Men’s Understanding of Their Role in the Transmission of BRCA1/2 Mutations within Their Family'. Sociology of Health \& Illness 28 (7): 969-88.

22. Hanson, Mark A., and Peter D. Gluckman. 2011. 'Developmental Origins of Health and Disease: Moving from Biological Concepts to Interventions and Policy'. International Journal 
This document is the preprint version of the article, and should be cited as:

Luca Chiapperino and Francesco Panese, 'Gendered Imaginaries: Situating Knowledge of Epigenetic Programming of Health', Sociology of Health \& Illness 40, no. 7 (1 September 2018): 1233-49, https://doi.org/10.1111/1467-9566.12779.

of Gynaecology and Obstetrics: The Official Organ of the International Federation of Gynaecology and Obstetrics 115 Suppl 1 (November): S3-5.

23. Hedlund, Maria. 2011. 'Epigenetic Responsibility’. Medicine Studies 3 (3): 171-83.

24. Heindel, Jerrold J., and Laura N. Vandenberg. 2015. 'Developmental Origins of Health and Disease: A Paradigm for Understanding Disease Cause and Prevention'. Current Opinion in Pediatrics 27 (2): 248-53.

25. Holliday, R. 1987. 'The Inheritance of Epigenetic Defects'. Science (New York, N.Y.) 238 (4824): 163-70.

26. Jasanoff, Sheila, ed. 2004. States of Knowledge: The Co-Production of Science and the Social Order. 1 New edition. London; New York: Routledge.

27. - 2015. 'Future Imperfect: Science, Technology, and the Imaginations of Modernity'. In Dreamscapes of Modernity: Socotechnical Imaginaries and the Fabrication of Power, edited by Sheila Jasanoff and Sang-Hyun Kim, 1-33. The University of Chicago Press.

28. Kenney, Martha, and Ruth Müller. 2016. 'Of Rats and Women: Narratives of Motherhood in Environmental Epigenetics'. BioSocieties, August.

29. Lappé, Martine. 2016. 'Epigenetics, Media Coverage, and Parent Responsibilities in the PostGenomic Era'. Current Genetic Medicine Reports 4 (3): 92-97.

30. Lupton, Deborah. 2013. The Social Worlds of the Unborn. Palgrave Macmillan.

31. Mansfield, Becky. 2012. 'Race and the New Epigenetic Biopolitics of Environmental Health'. BioSocieties 7 (4): 352-372.

32. . 2017. 'Folded Futurity: Epigenetic Plasticity, Temporality, and New Thresholds of Fetal Life'. Science as Culture, March, 1-25.

33. Mansfield, Becky, and Julie Guthman. 2015. 'Epigenetic Life: Biological Plasticity, Abnormality, and New Configurations of Race and Reproduction'. Cultural Geographies 22 
This document is the preprint version of the article, and should be cited as:

Luca Chiapperino and Francesco Panese, 'Gendered Imaginaries: Situating Knowledge of Epigenetic Programming of Health', Sociology of Health \& Illness 40, no. 7 (1 September 2018): 1233-49, https://doi.org/10.1111/1467-9566.12779.
(1): $3-20$.

34. Martin, Emily. 1991. 'The Egg and the Sperm: How Science Has Constructed a Romance Based on Stereotypical Male-Female Roles'. Signs 16 (3): 485-501.

35. Medina, José. 2011. 'Toward a Foucaultian Epistemology of Resistance: Counter-Memory, Epistemic Friction, and Guerrilla Pluralism'. Foucault Studies, no. 12: 9-35.

36. Meloni, Maurizio. 2017. 'Race in an Epigenetic Time: Thinking Biology in the Plural'. The British Journal of Sociology, March, n/a-n/a. https://doi.org/10.1111/1468-4446.12248.

37. Miska, Eric A., and Anne C. Ferguson-Smith. 2016. 'Transgenerational Inheritance: Models and Mechanisms of non-DNA Sequence-based Inheritance'. Science 354 (6308): 59-63.

38. National Research Council. 2011. Guide for the Care and Use of Laboratory Animals - Eight Edition. Washington, D.C: National Academies Press.

39. Nestlé Corporate Media Relations. 2014. 'Nestlé Boosts Research into Cutting-Edge Maternal Nutrition and Epigenetics'. Http:/Www.nestle.com. 29 December 2014. http://www.nestle.com/media/newsandfeatures/nestle-research-epigenetics.

40. Petchesky, Rosalind Pollack. 1987. 'Fetal Images: The Power of Visual Culture in the Politics of Reproduction'. Feminist Studies 13 (2): 263-92.

41. Pray, Leslie A. 2015. Examining a Developmental Approach to Childhood Obesity: The Fetal and Early Childhood Years: Workshop Summary. Washington, D.C: The National Academies Press.

42. Pugliese, Joseph. 2012. Biometrics: Bodies, Technologies, Biopolitics. Routledge.

43. Rapp, Rayna. 1999. Testing Women, Testing the Fetus: The Social Impact of Amniocentesis in America. The Anthropology of Everyday Life. New York: Routledge.

44. Reed, Kate. 2009. “It's Them Faulty Genes Again”: Women, Men and the Gendered Nature of Genetic Responsibility in Prenatal Blood Screening'. Sociology of Health \& Illness 31 (3): 343- 
This document is the preprint version of the article, and should be cited as:

Luca Chiapperino and Francesco Panese, 'Gendered Imaginaries: Situating Knowledge of Epigenetic Programming of Health', Sociology of Health \& Illness 40, no. 7 (1 September 2018): 1233-49, https://doi.org/10.1111/1467-9566.12779.

59.

45. Richardson, Sarah S., Cynthia R. Daniels, Matthew W. Gillman, Janet Golden, Rebecca Kukla, Christopher Kuzawa, and Janet Rich-Edwards. 2014. 'Society: Don't Blame the Mothers : Nature News \& Comment'. Nature 512 (August): 131-32.

46. Richardson, Sarah S., and Hallam Stevens, eds. 2015. Postgenomics: Perspectives on Biology after the Genome. Durham: Duke University Press.

47. Rilling, James K., and Larry J. Young. 2014. 'The Biology of Mammalian Parenting and Its Effect on Offspring Social Development'. Science 345 (6198): 771-776.

48. Romanus, Stephanie, Patrick Neven, and Adelheid Soubry. 2016. 'Extending the Developmental Origins of Health and Disease Theory: Does Paternal Diet Contribute to Breast Cancer Risk in Daughters?' Breast Cancer Research : BCR 18.

49. Rose, Nikolas. 2013. 'The Human Sciences in a Biological Age'. Theory, Culture \& Society 30 (1): $3-34$.

50. Sandelowski, Margarete. 1994. 'Separate, but Less Equal: Fetal Ultrasonography and the Transformation of Expectant Mother/Fatherhood'. Gender \& Society 8 (2): 230-45.

51. Strathern, Marilyn. 1992. Reproducing the Future: Anthropology, Kinship, and the New Reproductive Technologies. New York: Routledge.

52. Strickler, Jennifer. 1992. 'The New Reproductive Technology: Problem or Solution?' Sociology of Health \& Illness 14 (1): 111-32.

53. Szyf, Moshe. 2015. 'Nongenetic Inheritance and Transgenerational Epigenetics'. Trends in Molecular Medicine 21 (2): 134-44..

54. Thompson, Charis. 2005. Making Parents: The Ontological Choreography of Reproductive Technologies. Inside Technology. Cambridge, MA: MIT Press.

55. Waggoner, Miranda. 2017. The Zero Trimester: Pre-Pregnancy Care and the Politics of 
This document is the preprint version of the article, and should be cited as:

Luca Chiapperino and Francesco Panese, 'Gendered Imaginaries: Situating Knowledge of Epigenetic Programming of Health', Sociology of Health \& Illness 40, no. 7 (1 September 2018): 1233-49, https://doi.org/10.1111/1467-9566.12779.

Reproductive Risk. Reprint edition. Oakland, California: University of California Press.

56. Warin, Megan, Vivienne Moore, Tanya Zivkovic, and Michael Davies. 2011. 'Telescoping the Origins of Obesity to Women's Bodies: How Gender Inequalities Are Being Squeezed out of Barker's Hypothesis'. Annals of Human Biology 38 (4): 453-60..

57. Weaver, Ian C. G., Nadia Cervoni, Frances A. Champagne, Ana C. D’Alessio, Shakti Sharma, Jonathan R. Seckl, Sergiy Dymov, Moshe Szyf, and Michael J. Meaney. 2004. 'Epigenetic Programming by Maternal Behavior'. Nature Neuroscience 7 (8): 847-54.

58. Wells, J. C. 2014. 'Commentary: Paternal and Maternal Influences on Offspring Phenotype: The Same, Only Different'. International Journal of Epidemiology 43 (3): 772-74.

59. Wells, Jonathan C.K. 2010. 'Maternal Capital and the Metabolic Ghetto: An Evolutionary Perspective on the Transgenerational Basis of Health Inequalities'. American Journal of Human Biology 22 (1): 1-17.

60. Whitelaw, Emma. 2006. 'Epigenetics: Sins of the Fathers, and Their Fathers'. European Journal of Human Genetics 14 (2): 131-32.

61. World Health Organization, Commission on Ending Childhood Obesity, and World Health Organization. 2016. Report of the Commission on Ending Childhood Obesity.

62. Yehuda, Rachel, Nikolaos P. Daskalakis, Linda M. Bierer, Heather N. Bader, Torsten Klengel, Florian Holsboer, and Elisabeth B. Binder. 2016. 'Holocaust Exposure Induced Intergenerational Effects on FKBP5 Methylation'. Biological Psychiatry 80 (5): 372-80. 


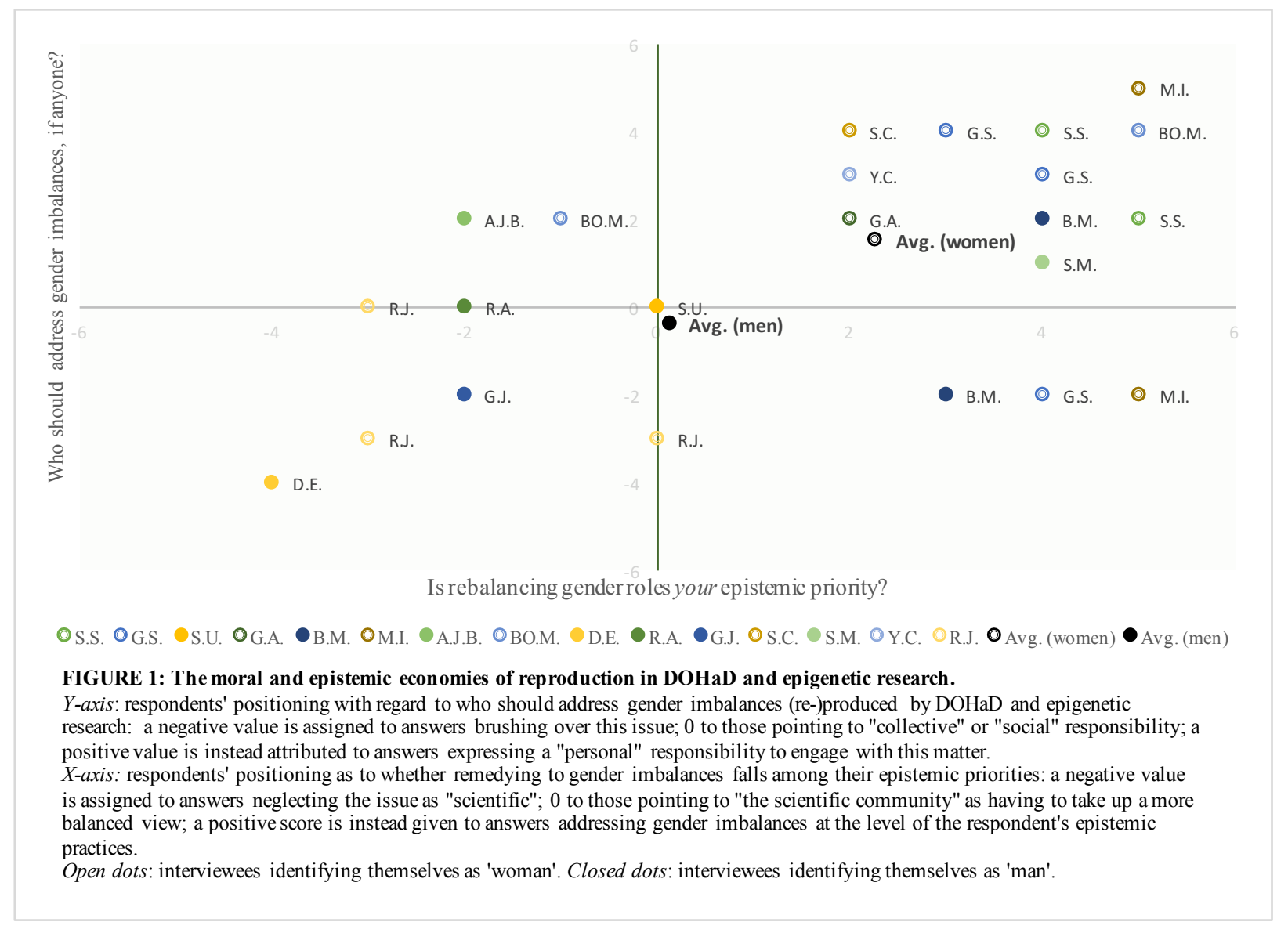

